\title{
Comparison of peripheral blood smear examination with automated haematology analyzer for diagnosing different types of anemia.
}

1. MBBS, DCP

Clinical Pathologist

Excel Labs Islamabad.

2. MBBS

Shaheed Zulfiqar Ali Bhutto Medical University (PIMS) Islamabad.

3. MBBS, M.Phil (Hematology), MHPE Assistant Professor Pathology Rawal Institute of Health Sciences Islamabad.

4. MBBS

Demonstrator Pathology

Federal Medical \& Dental College Islamabad.

5. MBBS

Shaheed Zulfiqar Ali Bhutto Medical University (PIMS) Islamabad.

6. MBBS, M.Phil (Chemical Pathology) Assistant Professor of Pathology Watim Medical \& Dental College Rawat.

Correspondence Address:

Dr. Rabiah Asghar

Excel Labs Islamabad.

rabiah111@gmail.com

Article received on: 29/10/2020

Accepted for publication: 02/02/2021
Rabiah Asghar ${ }^{1}$, Javera Tariq ${ }^{2}$, Nabeela Naeem ${ }^{3}$, Anila Zafar ${ }^{4}$, Khadija Qureshi $^{5}$, Shameela Majeed ${ }^{6}$

ABSTRACT... Objective: This study aims to determine diagnostic accuracy of peripheral blood smear and automated haematology analyzer and to determine frequency of different types of anemia diagnosed by peripheral blood smear and automated hematology analyzer. Study Design: Cross Sectional study. Setting: Department of Pathology, Rawal Institute of Health Sciences, Islamabad. Period: November 2015 to April 2016. Material \& Methods: Sample size of 149 suspected anemia patients was calculated using WHO calculator with $95 \%$ confidence interval. Diagnostic accuracy and frequency of anemia types was measured. Chi-square and fissure exact test and ROC curve analysis was applied and significant $(p<0.05)$ results were reported. Results: Total 149 patients were included in study. There were 42(28.2\%) male and $107(71.8 \%)$ female. Mean age of patients was 35.1 \pm 2.1 SD. Peripheral blood smear and automated haematology analyzer showed sensitivity (68\% vs $92 \%)$, specificity $(59 \%$ vs $88 \%)$, PPV (72\% vs $92 \%)$, NPV (55\% vs $88 \%)$ and diagnostic accuracy (64\% vs 91$)$ respectively. Most common type of anemia diagnosed with peripheral blood smear was microcytic hypochromic anemia with raised RDW $36.7 \%$ followed by normocytic normochromic anemia with raised RDW $13.3 \%$ and macrocytic anemia $(p=0.001)$ while in automated haematology analyzer microc ytic hypochromic anemia with raised RDW54.4\% followed by normochromic normocytic anemoia with normal RDW $11.1 \%(p=0.000)$. Conclusion: Automated haematyology analyzer had high diagnostic accuracy for diagnosis of anemia. Microcytic hypochromic anemia and normocytic normochromic are most common anemias diagnosed by peripheral blood smear and automated hematology analyzer and peripheral blood smear cannot be completely replaced by automated haemolytic analyzer. However, if both methods are used simultaneously, more accurate results can be obtained.

Key words: Anemia, Automated Haematology Analyzer, Peripheral Blood Smear.

Article Citation: Asghar R, Tariq J, Naeem N, Zafar A, Qureshi K, Majeed S. Comparison of peripheral blood smear examination with automated haematology analyzer for diagnosing different types of anemia. Professional Med J 2021; 28(10):1433-1437. https://doi.org/10.29309/TPMJ/2021.28.10.6179

\section{INTRODUCTION}

Anemia is a common hematological disorder affecting one third of population, globally. ${ }^{1}$ It is a common condition associated with significant increase in mortality, morbidity, work productivity reduction and neurological development impairment. ${ }^{2}$ Anemia is defined as decreased number of red blood cells or low hemoglobin/ hematocrit level. Moreover, World Health Organization (WHO) defined severe anemia as hemoglobin level $<8 \mathrm{~g} / \mathrm{dl}$ in all age groups other than under 5 years. ${ }^{3}$ Prevalence of anemia was approximately high in women of reproductive age $39 \%$, pregnant women $46 \%$ and children under 5 years $42 \%$ in $2016 .{ }^{4}$ Prevalence of anemia is high in low income countries like Pakistan where reported prevalence of anemia was $57.7 \%$ in 2019. ${ }^{5}$

Anemia etiology is dependent upon whether it is hyperproliferative or hypoproliferative (corrected reticulocyte count $>2 \%$ and $<2 \%$ respectively). Literature reported that hypoproliferative anemia is subdivided into three main categories depending upon mean corpuscular volume (MCV); 1) microcytic anemia MCV <80fl (Iron deficiency anemia, anemia of chronic diseases, siderblastic anemia, thalassemia and lead poisoning), 2) Normocytic anemia 80-100 fl (Anemia of chronic disease, real failure, aplastic anemia, pure red cell 
aplasia, myelofibrosis and multiple myeloma), 3) Macrocytic anemia MCV >100fl (Alcohol, liver disease, hypothyroidism, folate and vitamin B 12 deficiency, melody's plastic syndrome and drug induced causes). ${ }^{6}$

Diagnosis of anemia is usually done with peripheral blood smear or automated haematology analyzer. Peripheral blood smear is basic screening hematological tool for diagnosis, monitoring and understanding progression of anemia. The diagnostic relevance of peripheral blood smear is associated with understanding morphology of peripheral blood cells. Peripheral blood smear is still an important diagnostic tool in low and middle income countries even after advances in haematology automation and molecular techniques. ${ }^{7}$

Automated haematology analyzer is associated with integrated reticulocyte analysis, complete bloodcountanalysis, reticulocyte\% count, absolute reticulocyte count, reticulocyte hemoglobin content, microcytic cells $\%$, hypochromic cells $\%$ and immature reticulocyte fraction etc. ${ }^{8}$ Toppo et al. reported that auto analyzer is recommended as gold standard with high sensitivity $99.9 \%$ and diagnostic accuracy $80 \% .{ }^{9}$ However, limited data is available on diagnostic accuracy of peripheral blood smear. Present study aims to determine diagnostic accuracy of peripheral blood smear and automatic haematology analyzer and to determine frequency of different types of anemia diagnosed by peripheral blood smear and automatic hemolytic analyzer.

\section{MATERIAL \& METHODS}

A cross sectional study was conducted at Department of Pathology, Rawal Institute of Health Sciences. Study duration was 6 months (November 2015 to April 2016). A sample size of 149 patients was calculated using $26 \%$ prevalence of anemia ${ }^{10}$, $7 \%$ significance level and 95\% confidence interval using WHO calculator. Patients were selected through non probability (consecutive) sampling. Research approval was taken from ethical review board (RHIS-REC/057/20). Inclusion criteria was based upon age >18-60 years, both genders and patients suspected for anemia. Blood samples were drawn from each participant using aseptic precautions into ethylene diamante tetra acetic acid (EDTA) through disposable syringes. Blood samples were subjected to both testing methods (peripheral blood smear and automated haematology analysis) and hemoglobin levels in patients were measured. Patients with hemoglobin level $\leq 10.9 \mathrm{~g} / \mathrm{dl}$ were referred as anemic using Toppo et al. guidelines. ${ }^{9}$ Data was analyzed using SPSS version 25. Mean and standard deviation was calculated for continuous data like age. Percentage and frequency was calculated for nominal and categorical data like gender and types of anemia. Chi-square test and fissure exact test was applied. We found $p$ value $\leq 0.05$ was considered significant.

\section{RESULTS}

Peripheral blood smear testing showed 68\% sensitivity, 59\% specificity, PPV 72\%, NPV 55\% and diagnostic accuracy 64\%. Automated haematology analyzer showed $92 \%$ sensitivity, $88 \%$ specificity, 92\%PPV, 88\% NPV and 91\% diagnostic accuracy.

ROC curve analysis showed $63 \%$ accuracy of Peripheral blood smear while $90 \%$ accuracy on automated haematology analyzer for anemia diagnosis as shown in Figure-1 and 2.

Out of 149 patients males were 42 (28.2\%) and females were $107(71.8 \%) .1$. Mean age of patients was $35.1 \pm 2.1 S D$. There were $95(63.8 \%)$ patients in age group 18-35 years while 54(36.2\%) patients in 36-60 years age group.

Total of 112 cases showed microcytic hypochromic anemia with raised RDW (Red cell distribution width). Out of them on peripheral smear examination (17\%) cases showed dimorphic blood picture. Out of 7 cases that had microcytic hypochromic anemia with Normal RDW on automated analyzer 3(42.2\%) showed dimorphic blood picture on peripheral smear. Out of 11 cases having normochromic normocytic anemia with raised RDW 7(63.6\%) came out to be dimorphic on peripheral smear examination. Out of 9 cases that showed normochromic normocytic anemia with normal RDW 2(22.2\%) 
showed dimorphic blood picture. There were 10 cases of macrocytic anemia out of which $3(30 \%)$ showed dimorphic blood picture on peripheral smear examination.

\begin{tabular}{|l|c|c|c|c|c|}
\hline \multicolumn{1}{|c|}{ Types of Anemia } & $\begin{array}{c}\text { Automated } \\
\text { Analyzer }\end{array}$ & $\begin{array}{c}\text { Peripheral Smear } \\
\text { Examination }\end{array}$ & $\begin{array}{c}\text { Dimorphic Blood } \\
\text { Picture on PF }\end{array}$ & Total & P-Value \\
\hline MCHA with raised RDW & 112 & 93 & 19 & 84 & $<.001$ \\
\hline MCHA with normal RDW & 07 & 05 & 03 & 07 & $<.001$ \\
\hline NCNA with raised RDW & 11 & 06 & 07 & 11 & $<.001$ \\
\hline NCNA with normal RDW & 09 & 07 & 02 & 09 & $<.001$ \\
\hline Macrocytic anemia & 10 & 08 & 03 & 10 & $<.001$ \\
\hline Total & & & 149 & & \\
\hline
\end{tabular}

Table-I. Comparison of results automated haematology analyzer and peripheral blood smear.

\begin{tabular}{|l|c|c|}
\hline \multicolumn{1}{|c|}{ Types of Anemia } & $\begin{array}{c}\text { Automated } \\
\text { Analyzer }\end{array}$ & $\begin{array}{c}\text { Percentage } \\
\%\end{array}$ \\
\hline MCHA with raised RDW & 112 & 75.2 \\
\hline MCHA with normal RDW & 07 & 4.7 \\
\hline NCNA with raised RDW & 11 & 7.4 \\
\hline NCNA with normal RDW & 09 & 6.0 \\
\hline Macrocytic anemia & 10 & 6.7 \\
\hline Table-II. Automated analyzer findings with percentages.
\end{tabular}

Table-III. Peripheral smear findings with percentages.

\begin{tabular}{|l|c|c|}
\hline Diagnostic Parameters & $\begin{array}{c}\text { Peripheral } \\
\text { Blood } \\
\text { Smear }\end{array}$ & $\begin{array}{c}\text { Automated } \\
\text { Hemolytic } \\
\text { Analyzer }\end{array}$ \\
\hline Sensitivity & $68 \%$ & $92 \%$ \\
\hline Specificity & $59 \%$ & $88 \%$ \\
\hline Positive predictive value & $72 \%$ & $92 \%$ \\
\hline Negative predictive value & $55 \%$ & $88 \%$ \\
\hline Diagnostic accuracy & $64 \%$ & $91 \%$ \\
\hline
\end{tabular}

Table-IV. Diagnostic parameters of peripheral blood smear ad automated hemolytic analyzer.

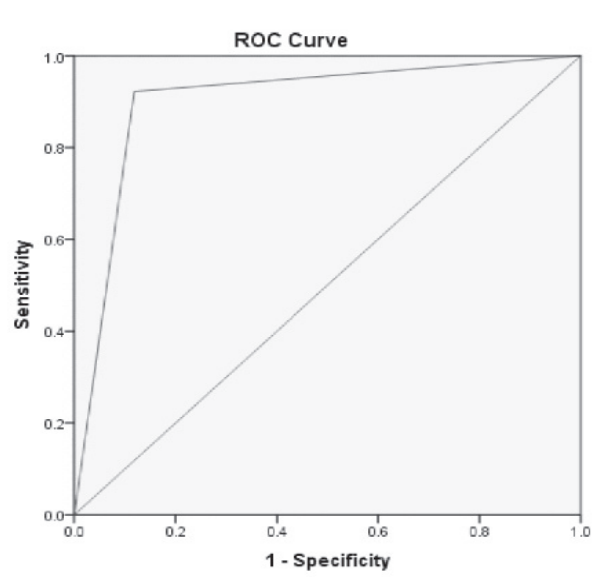

Diagonal segments are produced by ties

Figure-1. ROC curve analysis of peripheral Blood smear.

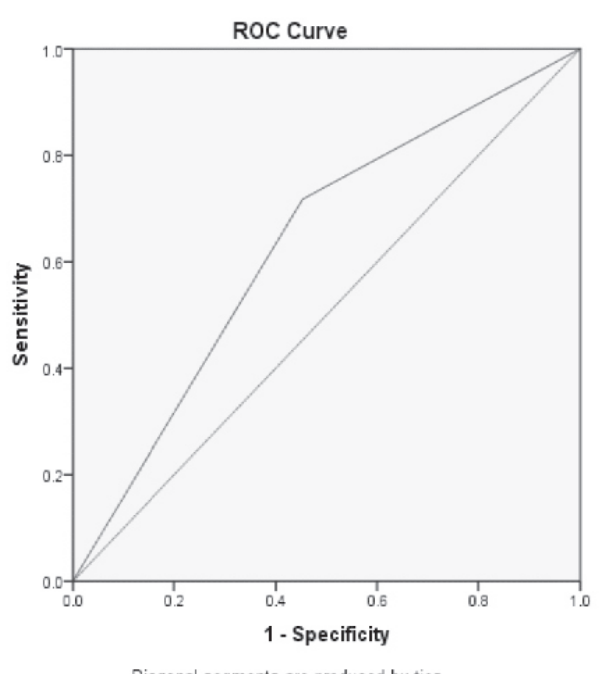

Diagonal segments are produced by ties.

Figure-2. ROC curve analysis of automated hematology analyzer.

\section{DISCUSSION}

Peripheral blood smear is an important part of 
laboratory investigation for anemia diagnosis. This manual process involves tedious observation, interobserver variation and time consuming process. ${ }^{11}$ This procedure motivated researchers to divert towards different algorithms and automated methods of diagnosis. Automated hematology analyzer is associated with accurate, rapid and avoids manual count bias. ${ }^{12}$

In present study, we found moderate diagnostic accuracy of peripheral blood smear $64 \%$. Comar et al reported that accuracy of peripheral blood smear is $46.3 \%$ with $70 \%$ efficacy equivalent, $23.7 \%$ false positive and $6.73 \%$ false negative. ${ }^{13}$ However, International society for laboratory haematology reported that efficacy of microscopic review rate is $73.8 \%$ with $10.5 \%$ false positive and $15.5 \%$ false negatives. ${ }^{14}$ Another similar study conducted by pratumvinit et al. reported that manual peripheral smear review had $87.13 \%$ efficacy accuracy with $2.98 \%$ false negative..$^{15}$ Xing et al. reported that diagnostic efficacy of peripheral blood review rate is $50.2 \%$ with $4.2 \%$ false negative rate and $18.7 \%$ false positive rate. ${ }^{16}$ Asad et al. reported that peripheral blood smear showed $91.3 \%$ sensitivity and $42 \%$ diagnostic accuracy with abnormal histogram. ${ }^{5}$

In present study, automated haematology analyzer showed $92 \%$ sensitivity and $91 \%$ diagnostic accuracy. Chapman reported that automated haematology analyzer had high sensitivity for blood cell count (CBC). ${ }^{17}$ Another similar study reported that automated haematology analyzer is gold standard for diagnosis of blood related diseases like anemia with high diagnostic accuracy $98 \% .^{18}$

In present study, most common type of anemia diagnosed with peripheral blood smear is microcytic hypochromic anemia with raised RDW $36.7 \%$ following normchromic normocytic anemia with raised RDW $13.3 \%$ while in automated haemolytic analyzer MCHC $54.4 \%$ following NCNC with normal RDW $11.1 \%$. Mukaya et al. reported $\mathrm{MCHC}$ anemia is most common anemia diagnosed by PBS and AHA $55.4 \%$ following NCNC $37.5 \% .{ }^{19}$ Kumar et al. reported that MCHC anemia $24.7 \%$ and NCNC anemia 12.64 with
$\mathrm{PBS}^{20}$ Sandhya I et al. reported $\mathrm{MCHC}$ anemia was diagnosed in $61 \%$ patients and CNCN $17 \%$ patients with PBS. ${ }^{21}$

Small sample size and conduction of study at single center limits generalizability of study.

\section{CONCLUSION}

Automated haemoatology analyzer had high diagnostic accuracy for diagnosis of anemia. Microcytic hypochromic anemia and normocytic normochromic are most common anemias diagnosed by peripheral blood smear and automated haematology analyzer and peripheral blood smear cannot be completely replaced by automated haemolytic analyzer. However, if both methods are used simultaneously, more accurate results can be obtained.

\section{Copyright $\odot$}

\section{REFERENCES}

1. Kassebaum NJ, Jasrasaria R, Naghavi M. A systematic analysis of global anemia burden from 1990 to 2010. Blood. 2016; 123(2): 615-624.

2. Black RE, Victora CG, Walker SP. Maternal and child undernutrition and overweight in low-income and middle-income countries. Lancet. 2016; 382(3): 427451.

3. World Health Organization. 2011. Haemoglobin concentrations for the diagnosis of anaemia and assessment of severity accessed. August 4, 2017.

4. Haider BA, Olofin I, Wang M. Anaemia, prenatal iron use, and risk of adverse pregnancy outcomes: Systematic review and meta-analysis. BMJ. 2016; 346(3): $\$ 3443$.

5. Ullah A, Sohaib M, Saeed F, lqbal S. Prevalence of anemia and associated risk factors among pregnant women in Lahore, Pakistan. Women Health. 2019; 59(6):660-671.

6. Triscott JA, Dobbs BM, McKay RM, Babenko O, Triscott E. Prevalence and types of anemia and associations with functional decline in geriatric inpatients. J Frailty Aging. 2017; 4(1):7-12. 
7. Novis DA, Walsh M, Wilkinson D, St. Louis M, BenEzra J. Laboratory productivity and the rate of manual peripheral blood smear review: A College of American Pathologists Q-Probes study of 95,141 complete blood count determinations performed in 263 institutions. Arch Pathol Lab Med. 2016; 130(3):596-601.

8. Lee HK, Kim SI, Chae H, Kim M, Lim J, Oh EJ, et al. Sensitive detection and accurate monitoring of plasmodium vivax parasites on routine complete blood count using automatic blood cell analyzer (DxH800(TM). Int J Lab Hematol. 2017; 34(2):201-7.

9. Toppo M, Pal K.D, Gour D, Melwani V, Dubey M, Mishra A. Comparison of performance of digital hemoglobinometer over automated hematology analyzer for hemoglobin estimation and its userfriendliness among the pregnant women in selected district hospitals of Madhya Pradesh. Indian J Community Med. 2019; 44(1): 31-34.

10. Patel KV. Epidemiology of anemia in older adults. Semin. Hematol. 2018; 45(4):210-7.

11. Jen P, Woo B, Rosenthal PE, Bunn HF, Loscalzo A, Goldman $L$. The value of the peripheral blood smear in anemic inpatients. The laboratory's reading v a physician's reading. Arch Intern Med. 2017; 143(6):1120-5.

12. Bourner G, Dhaliwal J, Sumner J. Performance evaluation of the latest fully Automated hematology analyzers in a large, commercial laboratory setting: A 4-way, side-by-side study. Lab Hematol. 2005; 11(4):285-97.

13. Comar SR, Malvezzi M, Pasquini R. Are the review criteria for automated complete blood counts of the international society of laboratory hematology suitable for all hematology laboratories? Rev Bras Hematol Hemoter. 2014; 36(3):219-25.
14. Lantis KL, Harris RJ, Davis G, Renner N, Finn WG. Elimination of instrument-driven reflex manual differential leukocyte counts. Optimization of manual blood smear review criteria in a highvolume automated hematology laboratory. Am J Clin Pathol. 2003; 119:656-62.

15. Pratumvinit B, Wongkrajang $P$, Reesukumal K, Klinbua C, Niamjoy P. Validation and optimization of criteria for manual smear review following automated blood cell analysis in a large university hospital. Arch Pathol Lab Med. 2013; 137(4):408-14.

16. Xing Y, Wang JZ, Pu CW, Shang K, Yan ZL, Bai YZ, et al. Establishment and evaluation of review criteria for ADVIA 120/2120 and different series of hematology analyzers. Zhonghua Yi Xue Za Zhi. 2010; 90(2):152630.

17. Chapman M. Hematology analyzers offer new technology and user-friendliness. Lab Med. 2000; 31(4):146-150.

18. Sharma P, Bhargava M, Sukhachev D, Datta S, Wattal C. LH750 hematology analyzers to identify malaria and dengue and distinguish them from other febrile illnesses. Int J Lab Hematol. 2014; 36:45-55.

19. Mukaya JE, Ddungu H, Ssali F, O'Shea T, Crowther MA. Prevalence and morphological types of anaemia and hookworm infestation in the medical Emergency ward, Mulago Hospital. Ugan DA S Afr Med J. 2019; 99(4):881-6.

20. Kumari S, Choudhary AK, Negi G. Prevalence of anemia among the general population of Bihar, India. Ind Med Gaz. 2019; 11(4):418-21.

21. Sandhya I, Muhasin T. Study of RBC histogram in various anemias. Journal of Evolution of Medical and Dental Sciences. 2014; 3(74):15521-34.

\begin{tabular}{|c|l|l|l|}
\hline \multicolumn{3}{|c|}{ AUTHORSHIP AND CONTRIBUTION DECLARATION } \\
\hline Sr. \# & \multicolumn{1}{|c|}{ Author(s) Full Name } & \multicolumn{1}{|c|}{ Contribution to the paper } & Author(s) Signature \\
\hline 1 & Rabiah Asghar & Author & \\
2 & Javera Tariq & Author & \\
3 & Nabeela Naeem & Author & \\
4 & Anila Zafar & Drafting the work. & \\
5 & Khadija Qureshi & Drafting the work. & \\
6 & Shameela Majeed & Revision of work & \\
\hline
\end{tabular}

